\title{
FROM SIGNALS TO REFORM NARRATIVE: REPUTATION REPAIR FOLLOWING CORPORATE ENVIRONMENTAL MISCONDUCT
}

\author{
GUIDO BERENDS \\ University of Groningen \\ Nettelbosje 2, 9747AE Groningen, The Netherlands \\ E-mail: g.h.j.berends@rug.nl \\ BJÖRN MITZINNECK \\ University of Groningen \\ JORDI SURROCA \\ University of Groningen
}

\section{INTRODUCTION}

Given the repercussions of corporate misconduct (e.g. Mishina, Dykes, Block, \& Pollock, 2010; Park \& Rogan, 2019), much research has sought to understand how organizations can restore their reputation following misconduct (Hersel, Helmuth, Zorn, Shropshire, \& Ridge, 2019). This research has however focused on individual signals, without considering that reputation is built over time (Fombrun \& Shanley, 1990; Ravasi, Rindova, Etter, \& Cornelissen, 2018). This is especially true in the aftermath of misconduct, when multiple signals may be needed to accumulate for reestablishing tarnished reputations (Elsbach, 2003; Hersel et al., 2019). Surprisingly little prior research has examined how organizations combine signals and what characteristics render such combinations successful (Connelly et al., 2011; Hersel et al., 2019). In this study, we seek to identify the conditions under which multiple signals distributed over time may be effective for reputation repair following corporate misconduct.

Integrating insights from narrative theory (Boje, 1991) into signaling research, we argue that signals to conjointly restore reputation need to follow a certain pattern and logic. In particular, signals need to tell a reform narrative, which we define as a temporal, discursive construction of signals that provide meaning for corporate audiences about the trustworthiness of corporate improvement efforts following misconduct. In particular, we argue firms need to introduce a credible protagonist for change and follow this signal up by a corrective claim signaling pursuant change efforts. We find empirical support that the effectiveness of multiple signals in restoring reputation rests upon their appropriate orchestration (kind and sequence) into a comprehensible and credible reform narrative. Our findings advance signaling theory by providing insights into how firms combine multiple signals over time. We contribute to research on greenwashing by offering a possible explanation for prior conflicting findings and we elaborate implications for the study of corporate misconduct.

\section{THEORY AND HYPOTHESES}

When a firm is implicated in misconduct, it runs the risk of being deemed undesirable, improper, and inappropriate by all or part of its stakeholders, and thus losing reputation (Hersel et al., 2019; Mishina et al., 2010). Signaling theory proposes that firms must send a signal of commitment to repair the damages caused to stakeholders and make changes to prevent 
misconduct from reoccurring (Connelly et al., 2011; Gomulya \& Mishina, 2017; Mishina et al., 2012; Pfarrer et al., 2008; Zavyalova et al., 2012). Yet, instances of misconduct also raise suspicion and thus redemptive signals may be dismissed (Gomulya \& Mishina, 2017; Zavyalova et al., 2012). Empirical evidence shows that signals following misconduct-even when conforming to conditions for signal effectiveness (cost, observability, and fit) identified by prior research (Connelly et al., 2011)-do not necessarily generate positive responses from corporate audiences (Elsbach, 2003; Lamin \& Zaheer, 2012; Shi \& Connelly, 2018; Westphal \& Zajac, 1998). For successful reputation repair signals must fulfill additional conditions. Notably, individual signals may not suffice.

\section{Combining Multiple Signals for Reputation Repair: Narrative Theory}

Firms typically send multiple signals in response to controversial events (Hersel et al., 2019). While some signaling research acknowledges that firms may seek to signal repetitively to keep their audiences updated as new information becomes available (Janney \& Folta, 2003), how multiple signals can be successfully combined remains ill understood (Connelly et al., 2011; Hersel et al., 2019). In fact, a multiplicity of signals increases the risk of confusing audiences (Vergne, 2012; Zuckerman, 2000).

To help us understand how firms may orchestrate signals to capture the attention of and convince skeptical audiences following misconduct, we turn to narrative theory (Boje, 1991). A narrative, as Cunliffe and colleagues (2004: 263) put it, is an oral or written "recital of a series of events ... a story." These logical discursive constructions guide sensegiving and sensemaking and can help corporate audiences comprehend a multiplicity of signals send by a firm (Boje, 1991; Cunliffe et al., 2004; Vaara et al., 2016). At the core of an effective narrative is a clear protagonist-the agent that propels the story forward-and a sequence of events or actions (Pentland, 1999).

\section{Reform Narrative}

Building on arguments and evidence from narrative theory, we propose that when responding to misconduct, firms need to introduce a credible protagonist to initiate change and a corrective claim that signals changed organizational behavior in response to corporate misconduct. It thus requires firms to send multiple coordinated signals over time.

Protagonist of the narrative. Introducing the protagonist is one important signal in the reform narrative. In an organizational narrative, the protagonist can be an individual, group, project, action, or the organization itself (Vaara et al., 2016). As stakeholders often attribute controversial behavior to the board or top management (Connelly et al., 2016; Westphal \& Zajac, 1998), a credible protagonist in a firms' reform narrative will likely need to come from the upper echelons of the organization. Indeed, firms often respond to incidents that challenge the integrity of their management by replacing one or more top executives (Connelly et al., 2016; Gangloff et al., 2016).

In signaling parlance, the substitution of an executive with credentials counter the controversy is considered a signal of intent (Hersel et al., 2019; Pfarrer et al., 2008). The appointment of a top executive seen as oppositional to the misconduct signals to firm audiences that (1) there has indeed been a violation of accepted behavior worthy of change in the organization and (2) the firm has the intention to take corrective action (Arthaud-Day, Dalton, 
Certo, \& Dalton, 2005; Hersel et al., 2019; Zhang \& Wiersema, 2009). For example, following an environmental scandal, firms may signal an intent to change by appointing an executive with known green credentials - i.e., through her/his affiliated with an environmental organization.

Hypothesis 1: An effective reputation repair following misconduct requires the introduction of a credible protagonist for reform.

Merely introducing the protagonist, however, is not a complete story. To offer a whole narrative of reform an entire sequence of events or actions needs to be signaled (Pentland, 1999). To successfully revert negative assessments, firms must therefore also take action that signals actual change (Pfarrer et al., 2008; Zavyalova et al., 2012).

Corrective claim. The second key aspect of a narrative is a signal that the intent of change is accompanied by associated action. To convince audiences of this, the corrective claim should be meaningfully linked to the protagonist and counter the type of misconduct (Ibarra \& Barbulescu, 2010). To illustrate, the appointment of a director with green credentials following environmental misconduct may be paired with increased environmental disclosure (Lewis, Walls, \& Dowell, 2014), signalling improved environmental performance. Together, the credible protagonist and associated corrective claim can convince audiences that the firm is in control and will prevent recurrences of misconduct, thereby reverting negative assessments (Connelly et al., 2011; Gomulya \& Mishina, 2017; Pfarrer et al., 2008).

\section{Hypothesis 2: An effective reputation repair following misconduct requires the introduction of a credible protagonist for reform and an associated corrective claim.}

In addition to a reform protagonist and associated corrective claim, narrative research suggests that effective stories should create a sense of plot (Barry \& Elmes, 1997; Martens et al., 2007), which is based on a carefully drafted temporal sequence of actions (Cunliffe et al., 2004; Pentland, 1999).

Temporal sequence of the reform signals. Narratives can only be understood by audiences when they follow a logical order over time (Cunliffe et al., 2004). This implies a meaningful sequence of accounts, where a perceived causal relationship exists between the actions taken (Vaara et al., 2016). As such, narratives in which, after a firm's misconduct, the first action is a signal of intent (i.e., the introduction of a credible reform protagonist) and the second action is a signal of associated change (i.e., corrective claim) are most likely to yield positive responses from corporate audiences (Pfarrer et al., 2008).

Hypothesis 3: An effective reputation repair following misconduct requires the introduction of a credible protagonist for reform first, followed by an associated corrective claim thereafter.

\section{METHODS}

\section{Research Context}

We test our theory by examining the signaling behavior in response to environmental misconduct of publicly traded firms between 2008 and 2019. To argue for the validity of our 
reform narrative concept, we conducted our empirical analysis in an extreme case: a setting where firms' redemptive signals are largely seen as symbolic. To test our arguments above, we examine the effectiveness of two subsequent signals of reform: 1) the introduction of a reform protagonist and 2) a signal of corrective claim. The introduction of a protagonist is operationalized as adjustments to the upper echelon (c.f. Westphal \& Graebner, 2010) to include an individual with green credentials, being affiliated with one of the 303 Environmental NonGovernmental Organizations (ENGOs) accredited by the United Nations (UN). We refer to such a signal as greening the upper echelon. Signal of corrective claim is operationalized as disclosing symbolic environmental actions-that is, increased external pro-environmental actions relative to internal pro-environmental actions (cf. Hawn \& Ioannou, 2016). We will refer to this signal as claiming environmental improvements.

\section{Data Collection, Matched Case Design, and Sample Construction}

To test our hypotheses, we assembled a panel dataset from four different sources. All publicly traded US firms from Thomson Reuters' ASSET4 database form the sampling frame for our study $(\mathrm{n}=2,508)$. In line with prior research, we examine reputation by collecting information on the tenor of media coverage (e.g., Deephouse, 2000). Specifically, we use the Event Sentiment Scores from RavenPack News Analytics to measure firm reputation and collected data on more than 85 million news stories related to 2,508 firms in our sample from 2008 till 2019. Data on corporate environmental misconduct was collected by combining information from ASSET4 with data on environmental penalties issued to companies by any U.S. agency retrieved from the Corporate Research Project. We gathered data on greening the upper echelon from the BoardEx database. As in some prior research (e.g., Hawn \& Ioannou, 2016), data on the disclosure of environmental activities came from ASSET4.

To test our hypotheses, we rely on a 1:1 matched samples research design (Pfarrer et al., 2010). Merging the data from the above-mentioned sources resulted in an initial sample of 2,508 US firms with 30,077 annual observations. This sample was used to create matched subsamples to compare firms engaging in different signaling strategies following environmental misconduct (see Table 1) ${ }^{1}$. By comparing similar firms with different signaling approaches with one another, we analyze the impact of different signaling strategies on reputation repair (cf. Zavyalova et al., 2012). To do so, we focus on an analytical window of four years. The window begins with $t_{0}$, the year in which the environmental misconduct occurs, followed by years $t_{1}$ and $t_{2}$ in which firms may send different signals seeking to repair their tarnished reputation and $t_{3}$ the year after the signals have been send to check if the effects of signals remain significant in the longer run ${ }^{2}$.

Table 1 about here

\footnotetext{
${ }^{1}$ Similar to Pfarrer et al. (2010), the matching was done based on industry, environmental score, volatility of a firm's reputation, media coverage, firm size. The matching was done blindly to prevent selection bias. After matching, t-tests comparing differences in the subsamples along the matching criteria revealed no significant differences $(p>0.05)$ between the treatment and control groups in each of the matched subsamples.

2 To remedy the fluctuations in a firm's reputation (Wartick, 2002) and to capture both short- and long-term reactions to the signals firms send, we create our reputation score as a rolling average of the yearly reputation score of the focal year $(t)$ and subsequent year $(t+1)$. As such, our empirical models include time variables $t_{0}, t_{1}$, and $t_{2}$.
} 


\section{Econometric Approach}

Due to the panel structure of the data and firms being nested in either the control group or treatment group we use multilevel mixed-effects linear regression. This method of analysis includes both between-subject (control vs treatment group) and within-subject effects (time) and is characterized as containing both fixed and random effects. In our specifications, the random effects account for random variability between the firms. To test our hypothesis, we set up a model with an interaction between the group and time variables, both specified as categorical variables, whilst controlling for other variables that are correlated with reputation (e.g. industry, yearly industry reputation, volatility of firm reputation, environmental performance, financial performance, signal costs, firm size, media coverage).

\section{RESULTS}

The time variable shows a negative and significant coefficient at $t_{1}$. That is, we observe a significant drop in the two-year average reputation after misconduct, confirming that corporate misconduct indeed damages the reputation of a firm if it does not adequately respond. We do not find support for our first hypothesis since greening the upper echelon alone does not significantly impact the reputation following environmental misconduct. We do not find evidence either that claiming environmental improvements alone significantly impacts reputation following misconduct. When firms combine these two signals-i.e., send multiple signals-in an unstructured way (i.e., by first claiming environmental improvements and then greening the upper echelon), it does not significantly impact reputation. As such, we find no support for Hypothesis 2. Related to our argument for a reform narrative, our models show that when firms first green their upper echelon and in the next year follow this up with claiming environmental improvements, they are able to significantly improve their reputation following misconduct. Both the interactions with $t_{1}$ and $t_{2}$ show a positive and significant effect on reputation, treatment $* \mathrm{t}_{1}(\mathrm{~b}=1.23, \mathrm{p}<0.01)$ and treatment $* \mathrm{t}_{2}(\mathrm{~b}=1.26, \mathrm{p}<0.05)$. That is, we find strong support for Hypothesis 3 , in line with our conceptualization of a reform narrative.

\section{DISCUSSION}

Our paper has several implications for extant theory. First, it contributes to research on signaling. By integrating insights from narrative theory (Boje, 1991; Cunliffe et al., 2004; Vaara et al., 2016) into signaling research (Connelly et al., 2011), we theorized and tested how firms construct a reform narrative that helps audiences interpret and give meaning to combinations of signals following misconduct. Our results demonstrate that reputation repair is most effective if firms introduce a protagonist of change as a signal of intent followed by a corrective claim as a signal of progressing change. Together, these signals inform corporate audiences that the firm has a strong commitment to meet stakeholder expectations and to implement the changes necessary to prevent transgressions from reoccurring.

Our study reveals the importance of considering the previously often underappreciated orchestration of signals for reputation repair. One signal affects the interpretation and effectiveness of a subsequent signal (cf. Gomulya \& Mishina, 2017) and thus signaling strategies need to be carefully crafted to be effective. Specifically, when multiple, sequenced, and coherent 
signals are conjointly used, a narrative is created which can alter stakeholders' perceptions of a firm, reestablishing lost reputation following corporate misconduct.

Notebaly, reform narratives appear able to repair reputation even when not all signal characteristics previously assumed to be necessary for signal effectiveness are met. In particular, individual signals combined into a reform narrative may be less costly than prior research would lead us to expect (Connelly et al., 2011; Gomulya \& Mishina, 2017). Inexpensive signals have long been argued to be readily dismissed by corporate audiences (Spence, 1973). For individual signals, our results support this notion. When firms only respond to misconduct with a symbolic corrective claim which is relatively cheap to send (sometimes also referred to as "cheap" talk), firms are unable to repair their reputation following misconduct (e.g. Connelly et al., 2011; Pfarrer et al., 2010; Zavyalova et al., 2012). Similarly, sending a signal of intent without demonstrating actual improvements, does not revert negative assessments from stakeholders. However, when these are combined in an orchestrated reform narrative, they are effective in restoring reputation.

Second, we contribute to research on corporate misconduct and corrective actions. We argue that while the different types of corrective actions identified by existing research may all aim to reduce negative effects of misconduct (Hersel et al., 2019), the way they influence stakeholder perceptions substantially differs. Our study shows that it is not only the type of corrective action that drives effectiveness. Rather, how multiple corrective actions are linked together and ordered over time is key.

Third, this study also enriches our understanding of greenwashing. Our results may offer an explanation for the conflicting findings (e.g. McDonnell \& King, 2013; Berrone, Fosfuri, \& Gelabert, 2017; Walker \& Wan, 2012) in this literature by supporting the idea that signals of environmental performance do not need to be costly to be effective as long as they form a compelling narrative.

\section{REFERENCES AVAILABLE FROM THE AUTHORS}

TABLE 1

\begin{tabular}{lll}
\hline \multicolumn{1}{l}{ Name } & Description \\
\hline 1 & No action a & $\begin{array}{l}\text { Firms that do not engage in either of the two signaling } \\
\text { strategies }\end{array}$ \\
2 & $\begin{array}{l}\text { Greening the upper } \\
\text { echelon }\end{array}$ & $\begin{array}{l}\text { Firms that only green their upper echelon one year after } \\
\text { they were involved in environmental misconduct. }\end{array}$ \\
3 & $\begin{array}{l}\text { Claiming environmental } \\
\text { improvements }\end{array}$ & $\begin{array}{l}\text { Firms that claim environmental improvements one year } \\
\text { after they were involved in environmental misconduct. }\end{array}$ \\
4 & Multiple signals & $\begin{array}{l}\text { Firms that claim environmental improvements one year } \\
\text { after they were involved in environmental misconduct } \\
\text { and the second-year green the upper echelon. }\end{array}$ \\
& & $\begin{array}{l}\text { Firms that green the upper echelon one year after they } \\
\text { were involved in environmental misconduct and the }\end{array}$ \\
& Reform narrative & second-year claim environmental improvements.
\end{tabular}

${ }^{a}$ Control group. As such, firms in this group are used as a baseline for comparing the firms that do take action in response to environmental misconduct (firms in groups 2-5). 